\title{
Do mudskippers and lungfishes elucidate the early evolution of four-limbed vertebrates?
}

\author{
Ulrich Kutschera ${ }^{1 *}$ and J Malcolm Elliott ${ }^{2}$
}

\begin{abstract}
Background: Recently, the origin of four-limbed vertebrates (tetrapods) was re-assessed, based on footprints and trackways that were made by early land animals almost 400 million years (my) ago. That is 18 my earlier than the oldest known tetrapod body fossils, such as Acanthostega and Ichthyostega from Greenland, and 10 my older than the earliest 'tetrapodomorph fishes' (Panderichthys, Tiktaalik etc.). These and other facts suggest that the first tetrapods may have thrived in the marine-influenced intertidal and/or lagoon zone as well as in brackish and freshwater environments associated with land vegetation, as previously thought.

Results: Here, we discuss the controversial question whether or not extant air-breathing fishes, such as mudskippers, amphibious gobioids that inhabit mangrove swamps, can be interpreted as living model organisms, with reference to the earliest land plants. In addition, recent developmental and behavioural studies on lungfishes (Dipnoi) are summarized and evaluated.

Conclusions: We conclude that mudskipping 'walking fishes' (Periophthalmus sp.) and Dipnoi (Protopterus sp.) shed light on the gradual evolutionary transition of ancient fishes to early tetrapods that occurred during the Devonian in muddy, salty waters. However, they are not the ancestors of tetrapods, because extant organisms cannot be progenitors of other living beings.
\end{abstract}

Keywords: Air-breathing fishes, Devonian, Fish-Tetrapod transition, Lungfishes, Macroevolution, Mudskippers

\section{Background}

Over the last two decades, the fossil record of the earliest tetrapods (defined here as vertebrates with digit-bearing limbs rather than paired fin-like limbs) has been considerably expanded. Several books (Clack 2002; Benton 2005; Shubin 2008) and an excellent review article published in this journal (Clack 2009) cover this topic in detail, so that the "fish to amphibian-transition" is one of the best documented macro-evolutionary processes elucidated so far. Can this key event in the history of life be illustrated in biology classes on extant vertebrates? No one knows the ecology and behaviour of the earliest tetrapods that made the transition from water to land, but it is possible that some extant fishes illustrate how the ecological challenges were met.

Fifty years ago, Osche (1962) proposed that mudskippers, extant amphibious fishes that inhabit tropical

\footnotetext{
* Correspondence: kut@uni-kassel.de

'Institute of Biology, University of Kassel, Heinrich-Plett-Str. 40, Kassel, D-34132, Germany

Full list of author information is available at the end of the article
}

mangrove swamps, may be regarded as "model organisms" to elucidate the transition from water to land. However, the "mudskipper-as-extant-model systemhypothesis" is still controversial. In the present article, which is in part based on our original studies on mudskippers and other teleost fishes (Elliott 1994; Kutschera 2005, 2006; Kutschera et al. 2008) we summarize some basic facts and definitions pertinent to the key question of whether or not some extant fishes elucidate processes that took place millions of years ago.

\section{Diversity of fishes and the origin of tetrapods}

Of the three classes of fishes, Agnatha (jawless fishes), Chondrichthyes (cartilaginous fishes) and Osteichthyes (bony fishes), species in the latter class are by far the most numerous. As well as having a skeleton made of bone, their teeth are fixed into the upper jaw and they have a lung opening into the gullet. There are two subclasses: the Actinopterygii (ray-finned fishes) and the Sarcopterygii (lobe-finned fishes, also called Choanichthyes in some classifications) (Figure 1). The latter are more precisely

\section{它 Springer}



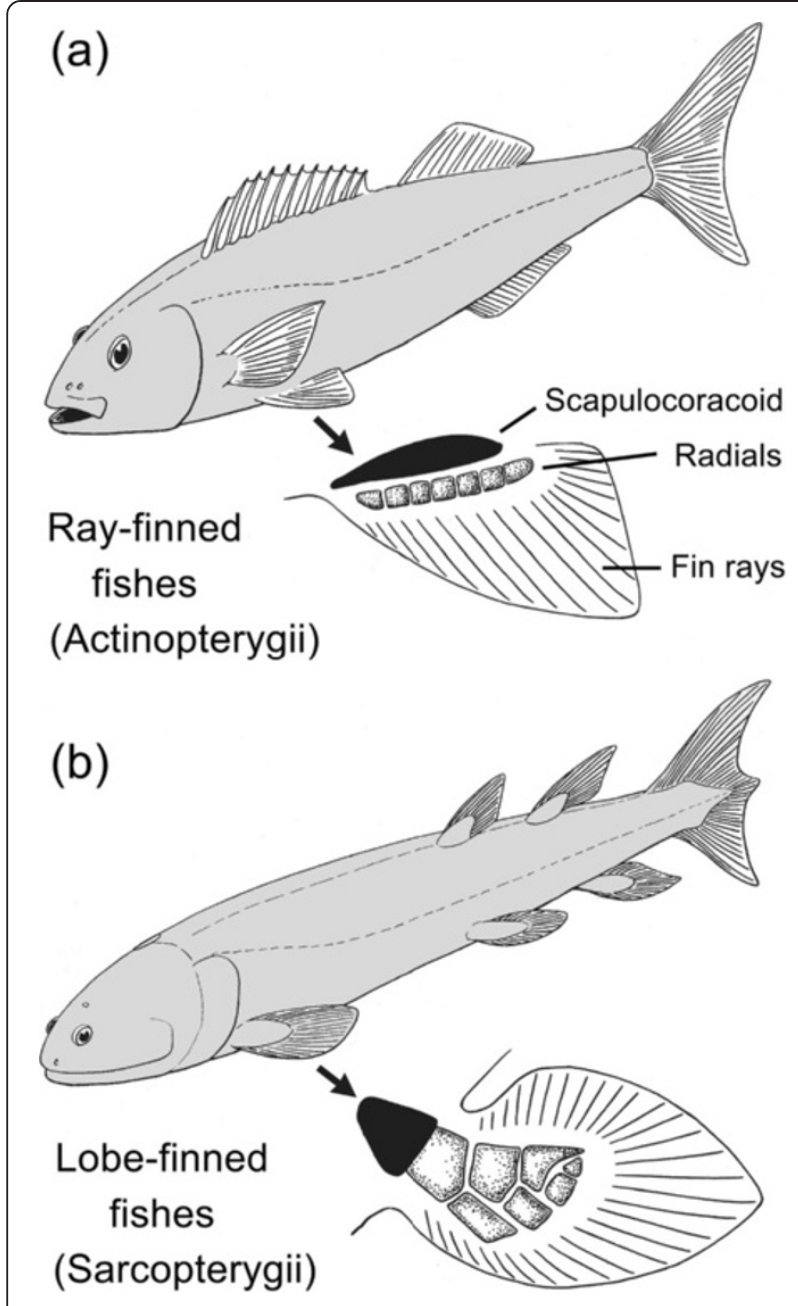

Figure 1 Basic features of the two classes of bony fishes, the ray-finned fishes (Actinopterygii) (a), and the lobe-finned fishes (Sarcopterygii) (b) (adapted from Buergin 1998).

described as fleshy-limbed vertebrates. Most bony fishes (ca. 27,000 described species) are in over 30 orders of the Actinopterygii, the vast majority of which are teleosts (Buergin 1998; Hurley et al. 2007). These fishes have their fins strengthened by bony rays and usually have two pairs of pectoral and pelvic fins, large eyes, no internal nostrils and a lung which is usually converted into a swim bladder (Figure 1a). In contrast, there are only two orders and seven extant species in the Sarcopterygii which have fins supported by large fleshy lobes containing bony skeletons (Johanson et al. 2007) (Figure 1b).

There is only one extant species in the first sarcopterygian order, the Crossopterygii, and that is the famous coelacanth, Latimeria chalumnae, which was first caught off the coast of East London, South Africa, in 1938 and described by J. L. B. Smith (1939). Until then, only fossils had been found in this order which was thought to have been extinct for 60 million years. This "living fossil" uses its heavy pectoral and pelvic fins to stir up the mud on the sea floor in search of prey, but does not use these paired fins to move against the substratum, as once proposed. There are six extant species in the second sarcopterygian order, the Dipnoi or lungfishes (Figure 2). They are found in fresh water in Australia, South America and Africa. As their name indicates, they can obtain their oxygen from the air and water, and are best described as "dual breathers"; hence Dipnoi, Dipnoans or Dipneusti (Carvalho and Goncalves 2011). It is unlikely that any extant lungfish was present when the first tetrapods invaded land. Lungfishes have evolved in parallel with terrestrial vertebrates and the extant species are well adapted to a highly specialised ecological niche. As will be shown later, air breathing has evolved independently in many species of Actinopterygii and one group, the mudskippers in the family Gobiidae, function well in a terrestrial environment and thus serve as possible "model organisms" to elucidate the transition from water to land. Therefore, all extant and extinct tetrapods belong to a once comprehensive group of vertebrates that are summarized under the taxon Sarcopterygii, with three extant taxonomic groups: the coelacanths, the lungfishes and the tetrapods (Benton 2005).

\section{The fish-tetrapod transition and the earliest land plants}

When palaeontologists discuss fossils from the Devonian period (ca. 416 to 359 mllion years ago, mya), they sometimes refer to the "Age of Fishes", because fish-like creatures represent the most abundant vertebrates of this geological time period (Gradstein et al. 2004). Fossil evidence documents that towards the end of the Devonian, the "fish-to-tetrapod transition" occurred between about 385 and 360 mya (Coates 1996; Clack 2002; Benton 2005; Ahlberg and Clack 2006; Coates et al. 2008; Shubin 2008), and today the "four-limbed vertebrates" are defined as follows. Tetrapods are vertebrate animals with four limbs bearing digits (fingers and toes), such as amphibians (salamanders etc.), reptiles (lizards etc.) and mammals (mice, apes, men etc.). In addition, the Tetrapoda include vertebrates that have reduced, modified or lost their limbs in the course of evolution, such as whales (mammals), snakes (reptiles) and birds (extant relatives of the extinct theropod dinosaurs) (Buergin 1998; Coates et al. 2008; Clack 2009).

Molecular data document that the Sarcopterygii, but not the coelacanth, are the closest living relatives of the Tetrapoda (Brinkmann et al. 2004). Extinct relatives of these fleshy-limbed vertebrates (Figure 1b), such as the ca. 380 my old fossil Dipterus, are the ancestors of the four-limbed vertebrates. Two years ago, well-preserved and dated tetrapod tracks were documented from Polish marine tidal flat sediments of early Middle Devonian age (ca. 398 mya). These tracks predate the oldest tetrapod skeletal remains by $18 \mathrm{my}$ and the earliest "tetrapodomorph" (elpistostegalian) fishes, such as Kenichthys, by ca 10 my (Janvier and Clément 2010; 

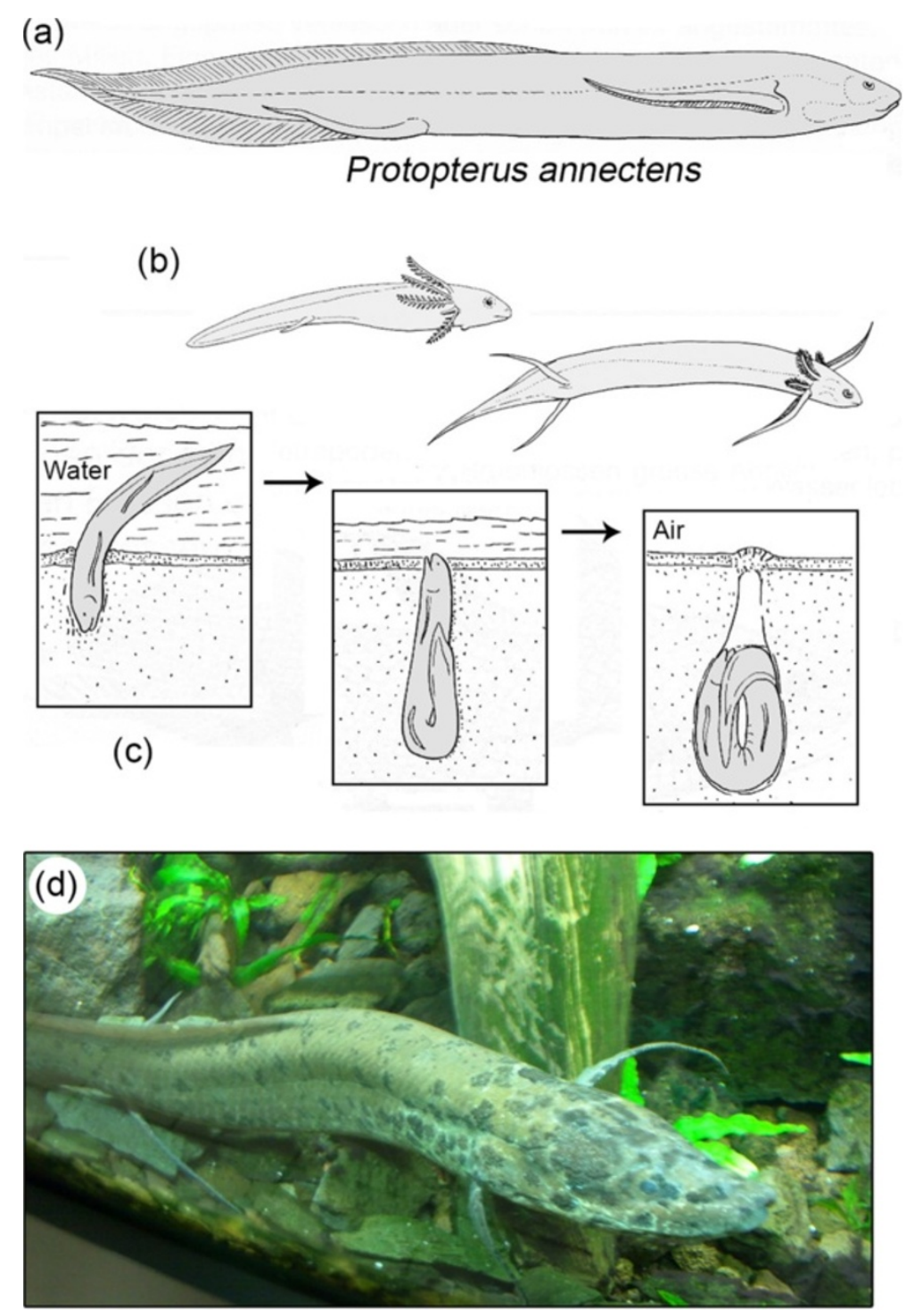

Figure 2 Morphology, ontogeny and behaviour of the African lungfish, Protopterus annectens. Schematic drawing of an adult specimen (a), larval development with gills that resemble those of extant amphibians (b), and behaviour during periods of drought in their natural environment (c). Adult specimen of the African lungfish, Protopterus annectens (d). These large sarcopterygians are the sister group to living tetrapods and may be viewed as model organisms to understand the vertebrate water-to-land transition (original photograph).

Niedźwiedzki et al. 2010). These data indicate that the first tetrapods, from which no fossils have yet been found, may have evolved in marine-influenced settings and invaded the mud of brackish lagoons.

In numerous earlier reconstructions of the fishto-tetrapod transition, it has been suggested that this macroevolutionary process took place over a time period of ca. 16 to $20 \mathrm{my}$ in the vegetated margins or surrounding seasonal 'flooded forest' environments of rivers, and, hence, in freshwater ecosystems (Romer 1941; Jarvik 1980; Schmalhausen 1968; Clack 2002). Moreover, it was proposed that early land plants were associated with this evolutionary step on land. Recent analyses of the colonization of the terrestrial landscape by green, multicellular plants (embryophytes), a process that pre-dated the early evolution of tetrapods, revealed the following insights (Niklas and Kutschera 2009, 2010). The embryophytes (Kingdom Plantae) represent a monophyletic group of photosynthetic eukaryotes that today comprise the non-vascular plant lineage (bryophytes), and the tracheophytes (i. e., lycophytes, ferns, horsetails and seed plants). The earliest embryophytes descended in freshwater environments from charophyte-like ancestors during the late Silurian (ca. 420 mya), and the earliest fossilized land plants (stems etc. with stomata) are ca. 410 my old (Cooksonia, 


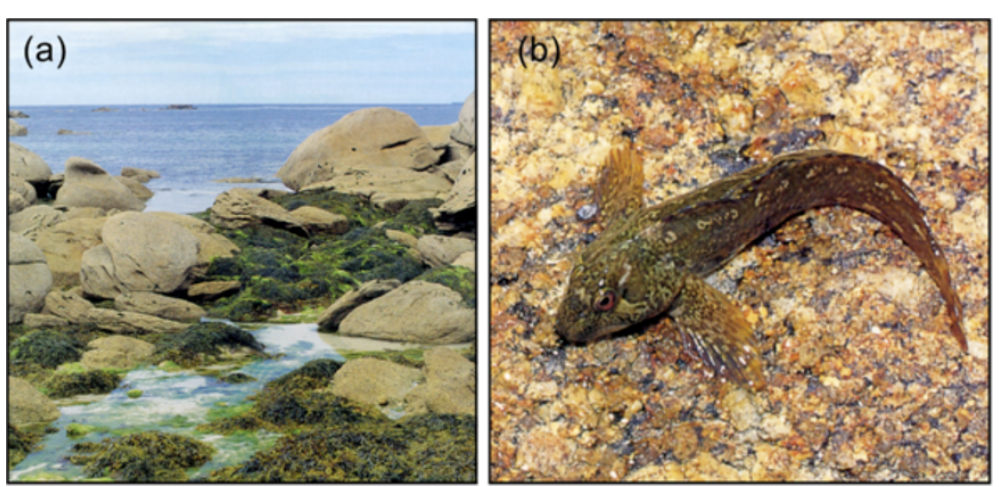

Figure 3 Natural habitat and representative specimen of an amphibious fish from Europe: tidal zone at the French Atlantic coast (Bretagne) (a), and the intertidal shanny, Blennius pholis (b). Shannies regularly leave the water, notably at night (adapted from Hofrichter 2000).

Rhynia, Zosterophyllum). Hence, the water-to-land transition in the plant kingdom pre-dated the evolution of the earliest tetrapods by at least 10 , possibly by 50 my (Gensel 2008; Niklas and Kutschera 2009, 2010).

It is, therefore, likely that these key events in the history of life on Earth occurred independently in different environments (freshwater ecosystems vs. marine intertidal or lagoon zones in plants and animals, respectively). The finding that the earliest tetrapods may have thrived in the "mud of a shallow marine lagoon" (Janvier and Clément 2010) is of importance with respect to the "mudskippers-as-model organisms" question that is discussed below.

\section{Air-breathing fishes: definition and occurrence}

Amphibians are regarded as the most basal class of terrestrial vertebrates, and in the majority of species, gill-breathing aquatic young (see Figure $2 \mathrm{~b}$ ) gradually change into lung and/or skin-breathing adults; hence, their class name (see Benton 2005). However, the ability to obtain oxygen from the air as well as the aquatic environment is shown by many species of fish. Graham (1997) summarized in detail the air-breathing species in 49 known families, all in the Osteichthyes. He notes that air-breathing fishes were probably present during the late Silurian period (438 to 408 mya), long before the evolution of the first amphibian tetrapods in the Middle Devonian (400 to 370 mya). Fish evolution and the development of air-breathing did not end with the appearance of the first amphibians, but has continued to the present day. Air-breathing in fish is the process of aerial gas exchange for respiration and requires an airbreathing organ. The chief advantage for the fish is the ability to survive in aquatic habitats that become deoxygenated seasonally, or at night, or permanently.

There are different kinds of air-breathing fishes. Aquatic air-breathing fishes remain in water and surface periodically to gulp air. This behaviour may be continuous in some species subjected to low oxygen concentrations and high water temperatures, or facultative in species
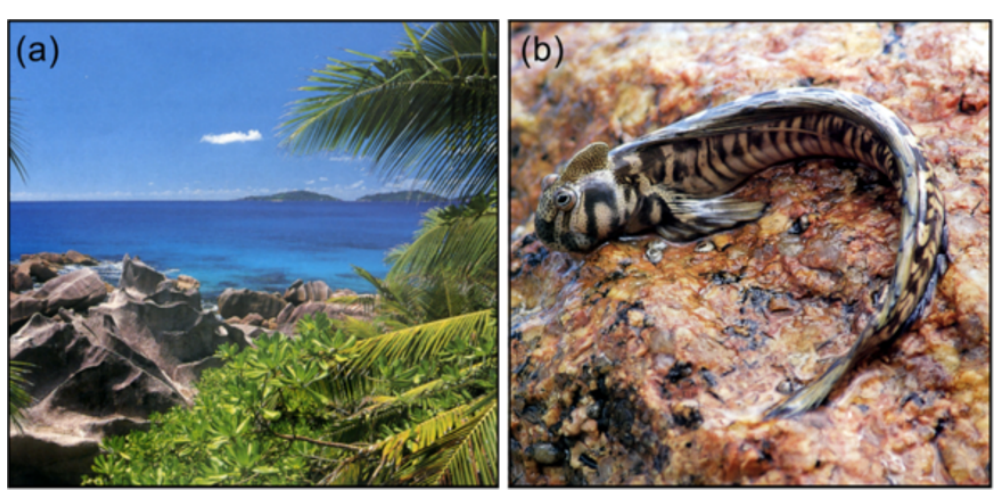

Figure 4 Natural habitat and representative specimen of an amphibious fish from the tropics: Seychellen-Islands, tidal zone, which is composed of Pre-Cambrian granite (a). The rock-jumper, Istiblennius edentulis (b), inhabits these moist areas and frequently leaves the water to walk on stones (adapted from Hofrichter 2000). 

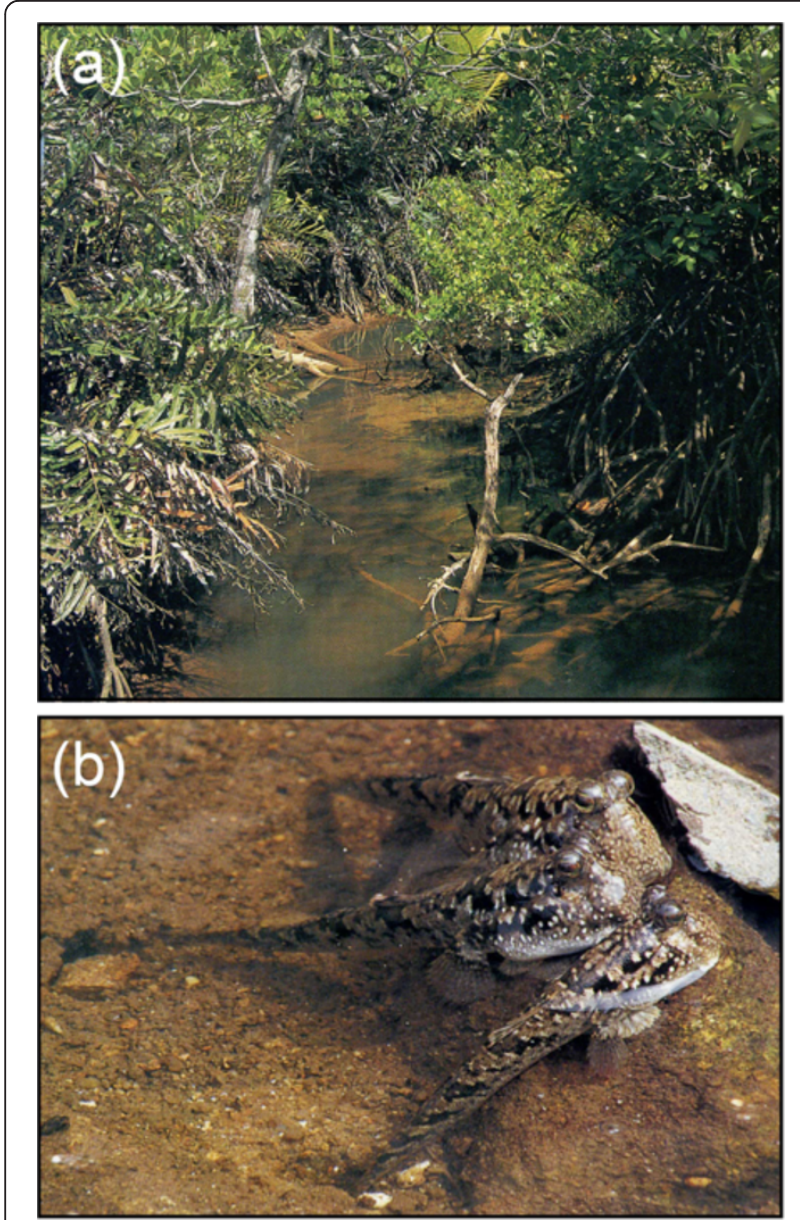

Figure 5 A mangrove forest, the habitat of the mudskipper, Periophthalmus argentilineatus (syn. $P$. sobrinus) (a). Three adult individuals of this species are depicted under natural conditions (b) (adapted from Hofrichter 2000)

subjected to occasional conditions unfavourable for aquatic respiration. In contrast, amphibious air-breathers emerge from the water to feed, rest, escape predators, find a mate and defend territories. Some species are active on land, such as the mudskippers that are the subject of the next section. Other species are inactive on land and become air-breathers when their aquatic habitat disappears during the tropical dry season. Some lungfishes are in this category and are confined in mud burrows until the rains return. They are without food and enter a hypometabolic state or even aestivate (see Figure 2).

Finally, there are those fishes that endure a brief exposure on land. A good example is the intertidal shanny, Blennius pholis, which occurs in tidal pools on the shore of the North Atlantic and Mediterranean (Figure 3). This species is not very active on land but will emerge from tidal pools when oxygen concentration in the water is low. Emergence occurs chiefly at night when humidity is high. Oxygen uptake occurs through the moist skin and by gulping air into the oesophagus with its numerous capillaries for gas exchange (Graham 1997). Another member of the same family (Blennidae) is the intertidal rock jumper, Istiblennius edentulis, from the tropics (Figure 4). Therefore, it is concluded that air-breathing pisces have evolved independently in many families of bony fish, and were present long before the evolution of terrestrial four-limbed vertebrates (Graham 1997; Hofrichter 2000).

\section{Mudskippers: amphibious fishes that climb trees}

Closely related to the blennies are fishes in the family Gobiidae. This is the largest family of marine fishes with about 200 genera and 1,500 species. Gobies occur in marine, mixohaline and fresh waters, and are probably the most abundant benthic fish species in the littoral zone of the tropics (Thacker, 2009). Air-breathing occurs in 15 genera, but the most impressive are the mudskippers in the genus Periophthalmus (Figures 5 and 6). The pelvic fins are modified to form a sucker for attachment to the substratum (Figure 6c). These highly active fishes are found on rocky shores, in mangrove swamps and on tidal flats throughout the Indo-Pacific Ocean and West Africa (Graham 1997; Hofrichter 2000).

Mudskippers are probably the most studied of airbreathing fishes and their biology has been reviewed by Clayton (1993), who noted the problems with their identification to species. As many as 100 species were once named but these have now been reduced considerably by the taxonomic revision by Murdy (1989). He recognized four mudskipper genera and 24 species: Periophthalmus (12 species), Periophthalmodon (3 species), Boleophthalmus (5 species) and Scartelaos (4 species).

The skin of a mudskipper is highly vascularised and this facilitates cutaneous respiration in both air and water. For the species of Periophthalmus in Figure 6, cutaneous respiration accounts for 50 to $60 \%$ of total aerial respiration and about $40 \%$ of total aquatic respiration (Graham 1997). As well as the sucker formed by the pelvic fins, mudskippers have well-developed pectoral fins that assist in their locomotion. They are capable of jumping and skipping across tidal mud flats, but also crawl with their body held stiff and pulled along by the alternate anterior extension and adduction of their large, highly dextrous, pectoral fins (Figure 6b,c). They also have well-developed turreted eyes and are active carnivores that can climb up rocks and even up the roots, trunk and lower branches of mangrove trees.

In an experimental study, prey recognition in P. barbarus was found to be similar to that in the European toad, Bufo bufo, when both species were offered small earthworms as food (Kutschera et al. 2008). Therefore, mudskippers may be regarded as "extant model organisms" to elucidate the vertebrate transition from water to land, and are intermediate 


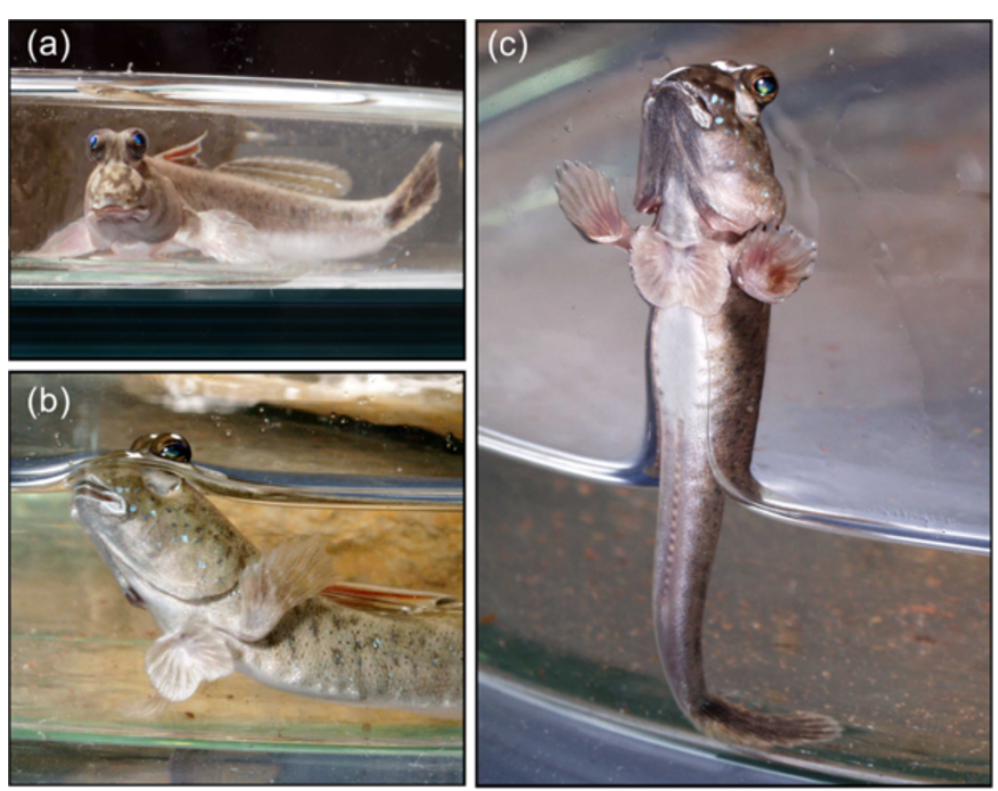

Figure 6 The Atlantic mudskipper (Periophthalmus barbarus) in an aquarium. This amphibious fish can live under water (a, b) and on land (c). Note the large pectoral fins of this ray-finned fish (Actinopterygii, see Figure 1a) (original photographs).

forms that display a number of anatomical and physiological macro-modifications of their body plan that enable them to live and forage for food on land. In other words, these fishes, that primarily seek food out of water and detect their prey organisms entirely by sight, are examples of macroevolution in progress (Kutschera 2006; Kutschera et al. 2008).

\section{Lungfishes and the evolution of walking}

As noted earlier, there are only seven extant species in the lobe-finned Sarcopterygii (exclusive of the Tetrapoda, Benton 2005). The deep sea coelacanth is obviously not an air-breather but does use its paired fins for slow swimming with alternating gaits similar to those seen in terrestrial amphibians. It was once assumed that coelacanths walked across the sea bottom because of the similarity between their fin morphology and the limbs of the early fossil tetrapods, but this is now considered incorrect (see Brinkmann et al. 2004). The remaining six species of sarcopterygians are all lungfishes in the Dipnoi and, as their name indicates, they can obtain oxygen from both air and water.

The species Neoceratodus forsteri has large fleshy fins and thick scales. This species is restricted to a small area of eastern Australia, is nocturnal, and lives in open waters and deep pools. It is mainly carnivorous with a maximum length of about $1.5 \mathrm{~m}$, and, unlike other lungfishes, it does not burrow or aestivate. Breathing in air is fairly continuous at low frequencies and its lung is ventilated by the same buccal force-pump mechanism found in other lungfishes (Graham 1997). It is the only extant lungfish with well-developed pectoral and pelvic fins that are greatly reduced in all the other species of lungfishes. Lepidosiren paradoxa has an eel-like shape and attains a length of about $1 \mathrm{~m}$. It is restricted to the Amazon and Pirana river basins of South America where it lives in swamps and shallow water where low oxygen concentrations are common, and seasonal droughts are frequent. It feeds on a mixture of invertebrates and small vertebrates, and its reduced limbs have tactile and chemosensory uses in orientation and prey detection in turbid water, but are of little use in locomotion (Graham 1997). L. paradoxa does not actively leave the water and during the dry season it lives in a moist burrow where it can survive for several months.

The remaining four species of lungfishes are all in the genus Protopterus, $P$. annectens (Figures 2a,d; maximum length $0.8 \mathrm{~m})$, P. dolloi $(0.3 \mathrm{~m})$, P. amphibius $(0.4 \mathrm{~m})$ and P. aethiopicus $(1.8 \mathrm{~m})$. They are found in tropical Africa and live in swamps, shallow pools, deep lakes and rivers. They are active predators but are also eaten by humans. All species develop like amphibians, i.e., they ontogenetically re-capitulate a "newt/salamander"-stage of gill development (Figure 2b). Finally, they become obligatory air-breathers at a young age and this enables them to survive low oxygen concentrations in many of their natural habitats (Graham 1997). When its habitat is subject to seasonal drying, the lungfish lives in a vertical burrow, constructs a mucous cocoon to prevent dehydration, and aestivates in dry mud for up to four years in the wild and six years in the laboratory. This survival strategy is depicted schematically in Figure 2c and described in detail by Greenwood (1986). 
In the early evolution of tetrapods, forelimbs and skulls became modified earlier than hind limbs so that the head and anterior of the body could be raised out of the water for air breathing, as seen in present-day mudskippers (Figure 6b). As noted above, the early tetrapods did not originate from mudskippers, which are teleosts (Actinopterygii) (Figure 1a), but from ancient lobe-finned sarcopterygians. Current views are that the lungfishes are more closely related to early tetrapods than the coelacanth, despite the latter being once regarded as an iconic "tetrapod ancestor" (Clack 2009).

The fins of $P$. annectens are long and slender (Figures 2a,d). A detailed experimental study by King et al. (2011) has shown that when this species is in an aquatic environment, it uses a range of pelvic fin-driven, tetrapod-like gaits, including walking and bounding, and is able to lift its body clear of the substratum by using its pelvic fins. These authors conclude that some basic features of tetrapod locomotion, including pelvic limb gait patterns, probably arose in sacopterygians before the origin of digital limbs and the invasion of land. The bipedal pelvic-driven gait produced patterns similar to those shown by some of the early fossil trackways, discussed above and previously attributed to tetrapods (Janvier and Clément 2010). King et al. (2011) conclude that trackways lacking unambiguous evidence of digits are now open to question, especially those from the Devonian when sarcopterygian fishes were diverse and abundant.

\section{General conclusions}

Five decades ago, when Osche (1962) wrote his theoretical paper, it was still suggested that the coelacanth, and not lungfishes, were the next living relatives of the Tetrapoda. Therefore, Osche (1962) discussed this topic from the "Latimeria-perspective" and did not take into account our modern view of this topic (Brinkmann et al. 2004). The "mudskipper-hypothesis" has remained controversial over the past five decades (Kutschera 2006; Kutschera et al. 2008). Here we show how mudskippers and lungfishes have coped with the ecological challenge of the water-to-land transition (Figures 2, 5, 6). It is possible that similar mechanisms enabled the gradual evolutionary transition of Devonian fishes to early tetrapods. Moreover, extant lungfishes (Figure 2) display a number of features that are reminiscent of those of the earliest tetrapods from the Devonian. The evidence is clearly circumstantial and assumes that convergent evolution occurred in mudskippers, lungfishes and the early tetrapods, an assumption that cannot be verified for the latter from the fossil record.

However, we must emphasise that neither mudskippers nor lungfishes are the ancestors of the Tetrapoda - extant organisms cannot be ancestral forms of other living beings. In other words, there exists no "Great Chain of Beings" in nature, and hence no "higher vs. lower organisms" or "advanced vs. primitive" can be distinguished. To make this point clear, men did not evolve from living chimpanzees, but from extinct hominoids, such as Sahelanthropus and related "ape-like bipedals" (Shubin 2008). We conclude that all extant species are of the same rank (Kutschera 2009; Kutschera 2011a, b) and represent the tips of one large tree of life that Darwin (1859) envisioned, and biologists of the 20th century corroborated using the techniques of DNA-sequence-based reconstructions of phylogenetic trees.

\section{Abbreviations}

My: million years; Mya: million years ago.

\section{Competing interests}

The authors declare that they have no competing interests.

\section{Author details}

${ }^{1}$ Institute of Biology, University of Kassel, Heinrich-Plett-Str. 40, Kassel, D-34132, Germany. 'Freshwater Biological Association, The Ferry Landing, Ambleside, Cumbria LA22 OLP, United Kingdom.

Received: 30 January 2013 Accepted: 30 January 2013

Published: 26 March 2013

\section{References}

Ahlberg, PE, \& Clack, JA. (2006). A firm step from water to land. Nature, 440(7085), $747-749$

Benton, M. (2005). Vertebrate palaeontology (3rd ed.). Oxford: Blackwell Science. Brinkmann, H, Venkatesh, B, Bremer, S, \& Meyer, A. (2004). Molecular proteincoding genes support lungfish and not the coelacanth as the closest living relatives of land vertebrates. Proceedings of the National Academy of Science of the United States of America, 101(14), 4900-4905.

Buergin, T. (1998). Fische im Strom der Zeit - 500 Millionen Jahre Entwicklungsgeschichte. St. Gallen: Museumsbrief 77/78

Carvalho, O, \& Goncalves, C. (2011). Comparative physiology of the respiratory system in the animal kingdom. The Open Biology Journal, 4, 35-46.

Clack, JA. (2002). Gaining ground: the origin and early evolution of tetrapods. Bloomington, IN: Indiana University Press.

Clack, JA. (2009). The fish-tetrapod transition: new fossils and interpretations. Evolution: Education and Outreach, 2(2), 213-223.

Clayton, DA. (1993). Mudskippers. Oceanography and Marine Biology: An Annual Review, 31, 507-577.

Coates, MI. (1996). The Devonian tetrapod Acanthostega gunnari Jarvik: postcranial anatomy, basal tetrapod relationships and patterns of skeletal evolution. Transactions of the Royal Society of Edinburgh: Earth Sciences, 87(3), 363-421.

Coates, Ml, Ruta, M, \& Friedman, M. (2008). Ever since Owen: changing perspectives on the early evolution of tetrapods. Annual Review of Ecology, Evolution and Systematics, 39, 571-592.

Darwin, C. (1859). On the origin of species by means of natural selection, or, the preservation of favoured races in the struggle for life. London: John Murray.

Elliott, JM. (1994). Quantitative ecology and the brown trout. Oxford: Oxford University Press.

Gensel, PG. (2008). The earliest land plants. Annual Review of Ecology, Evolution and Systematics, 39, 459-477.

Gradstein, FM, Ogg, JG, \& Smith, AG. (2004). A geologic time scale 2004. Cambridge: Cambridge University Press.

Graham, JB. (1997). Air-breathing fishes. Evolutions, diversity, and adaptation. London: Academic

Greenwood, PH. (1986). The natural history of African lungfishes. Journal of Morphology, 190(Suppl 1), 163-179.

Hofrichter, R. (2000). Der fisch auf dem Trockenen. Die Aquarien- und Terrarienzeitschrift, 53, 26-31.

Hurley, IA, Mueller, RL, Dunn, KA, Schmidt, EJ, Friedman, M, Ho, RK, Prince, VE, Yang, Z, Thomas, MG, \& Coates, MI. (2007). A new time-scale for ray-finned 
fish evolution. Proceedings of the Royal Society B Biological Sciences, 274(1609), 489-498.

Janvier, P, \& Clément, G. (2010). Muddy tetrapod origins. Nature, 463, 40-41. Jarvik, E. (1980). Basic structure and evolution of vertebrates. Vols. 1, 2. London: Academic.

Johanson, Z, Joss, J, Boisvert, CA, Ericsson, R, Sutija, M, \& Ahlberg, PE. (2007). Fish fingers: digit homologues in sarcopterygian fish fins. Journal of Experimental Zoology B (Molecular Development and Evolution), 308B(6), 757-768.

King, HM, Shubin, NH, Coates, MI, \& Hale, ME. (2011). Behavioral evidence for the evolution of walking and bounding before terrestriality in sarcopterygian fishes. Proceedings of the National Academy of Science of the United States of America, 108(52), 21146-21151.

Kutschera, U. (2005). Predator-driven macroevolution in flyingfishes inferred from behavioural studies: historical controversies and a hypothesis. Annals of the History and Philosophy of Biology, 10, 59-77.

Kutschera, U. (2006). Mudskippers undermine ID claims on macroevolution. Nature, 439(7076), 534

Kutschera, U. (2009). Charles Darwin's Origin of Species, directional selection, and the evolutionary sciences today. Naturwissenschaften, 96(11), 1247-1263.

Kutschera, U. (2011a). From the scala naturae to the symbiogenetic and dynamic tree of life. Biology Direct, 6(33), 1-20.

Kutschera, U. (2011b). Primitive ladder-of-life thinking has evolved. Science, 334(6061), 1347.

Kutschera, U, Burghagen, H, \& Ewert, JP. (2008). Prey-catching behaviour in mudskippers and toads: a comparative analysis. OnLine Journal of Biological Science, 8, 41-43.

Murdy, EO. (1989). A taxonomic revision and cladistic analysis of the oxudercine gobies (Gobiidae: Oxudercinae). Records of the Australian Museum Supp., $11,1-93$.

Niedźwiedzki, G, Szrek, P, Narkiewicz, K, Narkiewicz, M, \& Ahlberg, PE. (2010). Tetrapod trackways from the early middle Devonian period of Poland. Nature, 463(7277), 43-48.

Niklas, KJ, \& Kutschera, U. (2009). The evolutionary development of plant body plans. Functional Plant Biology, 36(8), 682-695

Niklas, KJ, \& Kutschera, U. (2010). The evolution of the land plant life cycle. New Phytologist, 185(1), 27-41.

Osche, G. (1962). Das Praeadaptationsphaenomen und seine Bedeutung für die Evolution. Zoologischer Anzeiger, 169, 14-49.

Romer, AS. (1941). Man and the vertebrates (3rd ed.). Chicago: The University of Chicago Press.

Schmalhausen, II. (1968). The origin of terrestrial vertebrates. New York: Academic Shubin, N. (2008). Your inner fish. New York: Vintage Books.

Smith, JLB. (1939). A living fish of Mesozoic type. Nature, 143, 455-456.

Thacker, CE. (2009). Phylogeny of Gobioidei and placement within Acanthomorpha, with a new classification: an investigation of diversification and character evolution. Copeia, 2009(1), 93-104.

doi:10.1186/1936-6434-6-8

Cite this article as: Kutschera and Elliott: Do mudskippers and lungfishes elucidate the early evolution of four-limbed vertebrates?. Evolution:

Education and Outreach 2013 6:8.

\section{Submit your manuscript to a SpringerOpen ${ }^{\circ}$ journal and benefit from:}

- Convenient online submission

- Rigorous peer review

- Immediate publication on acceptance

- Open access: articles freely available online

- High visibility within the field

- Retaining the copyright to your article

Submit your next manuscript at $\gg$ springeropen.com 